American Journal of Applied Sciences 6 (4): 652-655, 2009

ISSN 1546-9239

(C) 2009 Science Publications

\title{
Comparison the Proposed Probabilistic-Based Time-History and the Traditional PSHA Approach
}

\author{
A. Nicknam \\ Department of Civil Engineering, Iran University of Science and Technology, \\ Narmak, Tehran, Iran
}

\begin{abstract}
The main objective of this article is to demonstrate the ability of our technique in estimating the probabilistic-based time-history to be used in dynamic analysis of structures. The result of using our technique is compared with that of traditional approach proposed by Cornell (Cornell, 1968), in the form of response spectrum through a case study. Good agreement of the two approaches confirms the applicability/reliability of our technique having the merit of being dynamic form to be used in recognizing the vulnerability as well as performance evaluation of exiting important structures particularly in regions with lack of destructive earthquake information such as the region under study, Arge-Bam which was highly damaged through the destructive Bam earthquake in 2003.
\end{abstract}

Key words: Attenuation relation, hazard analysis, time-history, probability of exceedance

\section{INTRODUCTION}

The probabilistic seismic hazard methodology PSHA, currently used often referred to as the CornellMcGuire approach ${ }^{[13,14,15,27]}$, involves integrating the probabilities of experiencing a particular level of a selected strong motion parameter due to the total seismicity expected to occur in the area (about $300 \mathrm{~km}$ radius) of a site of interest during a specified life period. The attenuation characteristics of ground motion parameters (e.g., peak ground acceleration, velocity, or displacement or a spectral parameter ${ }^{[21,25]}$, are considered through an empirical attenuation law characterizing the source, the propagation medium, and the local site geology It is thus possible to provide the estimate of ground motion parameters with a specified confidence level (probability of exceeding).

From author point of view, the classical PSHA technique suffers from two points. The first point refers to its inability in providing the requirement of code of practices such as ASCE, i.e., appropriate ground motions having magnitudes, fault distance, and source mechanisms consistent with those that control the maximum earthquake ${ }^{[3,19,20]}$. This shortcoming arises from the point that the nature of current generation of attenuation relations is static which has been the main motivation of this study. More details is referred to ${ }^{[4]}$. The key point of our technique is the special form of our empirical attenuation relation in the form of Fourier spectral amplitudes which suggests the use of probabilistic-based time-history given the probability of exceedance at the site of interest.
The second point is the Poisson distribution of events in time used in current PSHA method by which the rate of earthquake occurrence is kept constant while it is quite postulated that this hypothesis does not agree with the experiment data. For this reason, the effect of non- homogenous and non-Poissonian distribution of earthquake recurrence time ${ }^{[23,26]}$, on the result of hazard analysis using our technique is studied (under publication) by the author.

Scope and objectives: A need for nonlinear analysis of structures using time history accelerations compatible with source mechanism, wave propagation and path form source to site, so called, looks to be essential for performance evaluation of new structures and existing facilities. This has been the main motivation of this study. The main objectives of this study are:

- To overcome the two above mentioned two weak points in currently used PSHA technique and presenting a modified version applicable for regions with lack of reliable data

- To demonstrate the possibility of our technique in estimating the probabilistic-based strong motion at the site of interest for performance evaluation of structures to be used in recognizing the vulnerability of exiting important structures particularly in regions with lack of destructive earthquake information

In the subsequent sections, Modern Probabilistic Seismic-Hazard Analyses is briefly explained. 
Thereafter, the Proposed Fourier amplitude spectrum ordinate attenuation relation, A brief explanation on our new PSHA technique and Comparison the results with those of Traditional approach are discussed. General conclusions drawn from the results is the last part of this article.

Modern Probabilistic Seismic-Hazard Analyses (PSHA): Mathematically, Probabilistic Seismic-Hazard Analyses (PSHA) involves a triple integration over earthquake sources, occurrence frequencies, and ground-motion attenuation relationships.

Let us assume that the level of seismic hazard is controlled by the total influence of all earthquakes that may occur in the region under consideration, and that the characteristics of ground motion expected during an earthquake of given $M$ and $R$ are lognormally distributed with standard deviation $\sigma_{\ln }$ y Then, for a single earthquake of $\mathrm{M}=\mathrm{m}$ at distance $\mathrm{R}=\mathrm{r}$, the probability that ground motion parameter $\mathrm{Y}$, will not exceed a given value $\mathrm{y}$, may be estimated according to Eq. 1.

$$
\begin{aligned}
& \gamma(\mathrm{y})=\sum v \mathrm{P}[\mathrm{Y} \geq \mathrm{y}]
\end{aligned}
$$

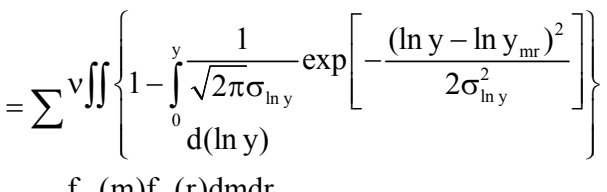

Where, $v$ is the rate of seismicity, $f_{M}(m)$ and $f_{R}(r)$ are the probability density function (PDF) of earthquake magnitude $M$ and epicentral/focal distance $R$, respectively. $\ln \mathrm{y}_{\mathrm{mr}}$ and $\sigma_{\ln \mathrm{y}}$ are the median and standard deviation at $\mathrm{m}$ and $\mathrm{f}$, which are determined by attenuation law used in the model ${ }^{[5,6,7,12]}$.

$$
\int_{0}^{y} 1 / \sqrt{2 \pi} \sigma_{\ln y} \exp \left[-\left(\ln y-\ln y_{m r}\right)^{2} / 2 \sigma_{\ln y}^{2}\right] d(\ln y)
$$

is referred to as attenuation relation (law) with variability $\varepsilon$. More details are given in Bommer ${ }^{[1,2,8]}$.

Within the last decade, providing inelastic dynamic response characteristics of structures has been extensively progressed due to the importance of the problem ${ }^{[18,24]}$ and the simple availability of high speed and memory computers. On the other hand, owing to the difficulties arises from the lateral load pattern (vertical load distribution), it is quite postulated that time-history analysis approach results in more reliable performance evaluation of structures. This is the main merit of our technique in comparison to the traditional PSHA method.

Proposed Fourier amplitude spectrum ordinate attenuation relation: An attenuation relation, for bed rock is proposed which reflects the attenuated Fourier spectral amplitude corresponding to each frequency at the site of interest in the following form.

$$
\ln \mathrm{Y}=\mathrm{C}_{1}+\mathrm{C}_{2} \cdot \mathrm{M}-\mathrm{C}_{3} \cdot \ln \mathrm{R}-\mathrm{C}_{4} \cdot \mathrm{R}+\varepsilon \cdot \sigma
$$

Where $\ln$ represents the natural logarithm, $\mathrm{Y}$ is the strong motion parameter (spectral amplitude in this study), $\mathrm{M}$ is earthquake magnitude, $\mathrm{R}$ is a measure of source-to-site distance. The constant coefficients $\mathrm{C}_{1}$, $\mathrm{C}_{2}, \mathrm{C}_{3}, \mathrm{C}_{4}, \mathrm{C}_{5}, \mathrm{C}_{6}$ and finally the standard deviation of $\ln \mathrm{Y}$, were calculated through a regression procedure. The coefficients of Eq. 3 are calculated corresponding to a predefined frequency ranges (e.g., $0.2-12 \mathrm{~Hz}$ ), using the least square approach.

A brief explanation on our PSHA technique ${ }^{[4]}$ : Our technique consists of four steps: a) Generating sufficient acceleration time histories for the site under consideration using the currently used kinematic stochastic synthesis strong motion approaches. b) Producing an attenuation relation by which the Fourier spectral amplitudes of generated strong motions are attenuated through assumed sources-path and soil beneath the site. Table 1 shows the regression coefficients of the proposed attenuation law for the Bam region for stiff site soil as a case study. For this purpose, the Fourier spectral amplitudes of time series, corresponding to level of hazard under consideration, are calculated using the traditional approach, Eq. 1 with a slightly difference as shown below:

$$
\begin{aligned}
& v(\omega)=\sum v P[a(\omega)>A(\omega)]
\end{aligned}
$$

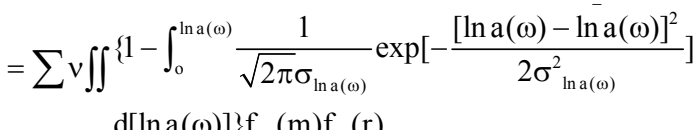

Where a $(\omega)$ is Fourier spectral amplitude of generated strong motion corresponding to frequencies $\omega$. The term

$$
\int_{0}^{\ln \mathrm{a}(\omega)} 1 / \sqrt{2} \sigma \mathrm{a}(\omega) \exp \left[-(\ln \mathrm{a}(\omega)-\ln \mathrm{a}(\omega))^{2} / 2 \sigma_{\ln (\omega)}^{2}\right] \mathrm{d}[\ln \mathrm{a}(\omega)]
$$

Equation is attenuation relation with specified mean value $\mathrm{a}(\omega)$ and standard deviation which its coefficients are identified as long as the frequency from $0.2-12 \mathrm{~Hz}$ is selected Table 1 . 
Am. J. Appl. Sci., 6 (4): 652-655, 2009

Table 1: Regression coefficients of the proposed attenuation law for the Bam region for stiff site soil

\begin{tabular}{llllllll}
\hline Fre. $(\mathrm{Hz})$ & C1 & C2 & C3 & C4 & C5 & C6 & Sigma \\
\hline 0.2 & -7.77168 & 2.786979 & 2.303363 & 0.013939 & 1.134865 & -0.013198 & 0.630 \\
0.5 & -5.82666 & 2.115710 & 1.519410 & 0.000856 & 1.396614 & -0.006683 & 0.410 \\
1.0 & -3.33763 & 1.397829 & 0.900167 & -0.967803 & -5.282250 & -0.001886 & 0.400 \\
1.5 & -3.13177 & 1.328265 & 0.817409 & -0.762636 & -5.519200 & -0.000523 & 0.300 \\
2.0 & -2.62977 & 1.282662 & 0.861771 & -0.675522 & -5.314170 & -0.001333 & 0.325 \\
3.0 & -2.26966 & 1.210415 & 0.853568 & -0.788122 & -5.477240 & -0.001192 & 0.290 \\
4.0 & -2.29123 & 1.191819 & 0.834145 & -0.754855 & -5.845350 & -0.000537 & 0.275 \\
5.0 & -2.09866 & 1.155943 & 0.880969 & -1.115160 & -5.567820 & -0.001283 & 0.270 \\
6.0 & -2.10268 & 1.161648 & 0.942846 & -3.275200 & -5.535500 & -0.001895 & 0.280 \\
7.0 & -2.12003 & 1.140246 & 0.938186 & -3.902120 & -5.744630 & -0.001526 & 0.305 \\
8.0 & -2.64027 & 1.156421 & 0.910915 & -49.22380 & -0.877190 & -0.002087 & 0.330 \\
9.0 & -2.54240 & 1.168919 & 0.997558 & -2.374980 & -4.926480 & -0.002679 & 0.295 \\
12.0 & -3.47160 & 1.168862 & 0.828566 & 0.292845 & -3.649140 & 0.000497 & 0.340 \\
\hline
\end{tabular}

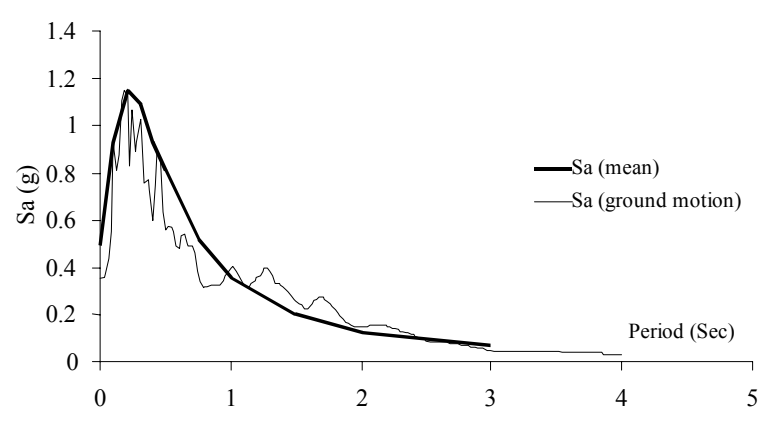

Fig. 1: Schematically comparison of the proposed technique with traditional approach in estimating $10 \%$ probability of exceedence for bed rock of Arg-e-Bam site. The smoothed plot shows the $\% 5$ damping response spectra while the other plot demonstrates that of the proposed technique

Another parameters are those of traditional formula, Eq. 1.

Finally, the estimated Fourier spectral amplitudes is converted into time domain as the probabilistic time history. More details are given in ${ }^{[4]}$.

Comparison the results with those of Traditional approach: An empirical attenuation relation based on our technique has been developed for Keman Province in Iran for bed rock sites. The proposed attenuation coefficients are shown in Table 1 and Fig. 1 demonstrates the comparison of response spectrum obtained from traditional PSHA and response spectrum corresponding to the estimated time-history at ArgeBam site with $10 \%$ probability of exceedence. Good agreement of these two methods confirms the applicability/reliability of our technique.

\section{CONCLUSION}

As previously mentioned, our PSHA technique ends with a probability-based time history corresponding to predefined probability of exceedance such as 50,10 and/or $2 \%$. The merit of such time history is its ability in performing dynamic analysis of structures rather than those of traditional approaches which are statically-based family of analyzing. Hence, our technique is useful in performance evaluation of structures to be used in recognizing the vulnerability of exiting important structures particularly in regions with lack of destructive earthquake information such as the region under study, Arge-Bam.

\section{REFERENCES}

1. Abrahamson, N.A. and W.J. Silva, 1997. Empirical response spectral attenuation relations for shallow crustal earthquakes. Seismological Res. Lett., 68: 94-127.

2. Abrahamson, N.A. and J.J. Bommer, 2005. Probability and uncertainty in seismic hazard analysis. Earthquake Spectra, 21: 603-607.

3. ASCE-7, 2005. American Society of Civil Engineers, Minimum Design Loads for Buildings and Other Structures.

4. Nicknam, A., A. Yazdani and S. Yaghmaei Sabegh, 2008. Predicting probabilistic-based strong ground motion time series for citadel of ARG-EBAM (sough east of Iran), J. Earthquake Eng.,

5. Elnashai, A.S., N.N. Ambraseys and D.M. Boore, 2003. Prediction of ground motion using the stochastic method. Pure Appl. Geophys, 160: 635-676.

6. Boore, D.M. and G.M. Atkinson, 1992. Source spectra for the 1988 Saguenay, Quebec, earthquake. Bull. Seism. Soc. Am., 82: 683-719.

7. Boore, D.M. and W.B. Joyner, 1997. Site amplification for generic rock sites. Bull. Seism. Soc. Am., 87: 327-341.

8. Bommer, J.J., 2006. Re-thinking seismic hazard mapping and design return periods. In: Proceedings, First European Conference on Earthquake Engineering, Geneva, pp: 1304. 
9. Bommer, J.J. and N.A. Abrahamson, 2006. Who do modern probabilistic seismic hazard analyses lead to increased hazard estimates Bull. Seismol. Soc. Am., 96: 1967-1977.

10. Beyer, K. and J.J. Bommer, 2006. Relationships between median values and aleatory variabilities for different definitions of the horizontal component of motion. Bull. Seismol. Soc. Am., 94: 1512-1522.

11. Campbell, K.W., 1981. Near-source attenuation of peak horizontal acceleration. Bull. Seismological Soc. Am., 71: 2039-2070.

12. Campbell, K.W., 1997. Empirical near source attenuation relationship for horizontal and vertical components of peak ground acceleration, peak ground velocity and pseudo-absolute response spectra. Seismological Res. Lett., 68: 154-179.

13. Christodoulou, A. and D. Hatzfeld, 1988. Threedimensional crustal and upper.

14. Cornell, C.A., 1968. Engineering seismic risk analysis. Bull. Seism. Soc. Am., 58: 1583-1606.

15. Cornell, C.A. and E.H. Van Marke, 1969. The major influences on seismic risk. In: Proceeding 3rd World Conference on Earthquake Engineering, Santiago, Chile, A-1, pp: 69-93.

16. Cornell, C.A., 1971. Probabilistic analysis of damage to structures under seismic loads. In: Dynamic Waves In Civil Engineering: Proceedings Of A Conference Organized By The Society For Earthquake And Civil Engineering Dynamics, Howells, D.A. I.P. Haigh and C. Taylor (Eds.). John Wiley, New York, pp: 473-493.

17. Campbell, K.W., 1997. Empirical near-source attenuation relationships for horizontal and vertical components of peak ground acceleration, peak ground velocity and pseudo- absolute acceleration response spectra. Seismological Res. Lett., 68: 154-179.
18. Fajfar P. and M. Fischinger, 1988. N2 method for nonlinear seismic analysis of regular structures. Proceedings of the 9th World Conference on Earthquake Engineering, Tokyo-Kyoto, Japan, pp: $111-116$

19. FEMA, 1997. NEHRP guidelines for the seismic rehabilitation of building. Report FEMA 273, Federal Emergency Management Agency, Washington, D.C.

20. FEMA, 2000. Prestandard and commentary for the seismic rehabilitation of building. Report FEMA 356, Federal Emergency Management Agency, Washington, D.C.

21. Gupta, I.D., 1991. A note on computing uniform risk spectra from intensity data on Earthquake occurrence. Soil Dyn. Earthquick Eng., $10 ; 407-413$.

22. Gulkan P. and M.A. Sozen, 1974. Inelastic of reinforced concrete structures to earthquake motions. ACI J., 71: 604-610.

23. John E. and D.W. Chambers, 2007. Nonpoissonian earthquake clustering and the hidden markov model as bases for earthquake forecasting in California. Seismological Res. Lett., 78: 65.

24. Krawinkler H. and G.D.P.K. Seneviratna, 1998. Pros and cons of a pushover analysis of seismic performance evaluation. Eng. Struct., 20: 452-464.

25. Lee, V.W. and M.D. Trifunac, 1985. Uniform risk spectra of strong earthquake ground motion: NEQRISK, Report CE 85-05, Dept. of Civil Eng., Univ. of Southern California, Los Angeles, California, U.S.A.

26. Luigi Palatellaa, 2004 Non-Poisson distribution of the time distances between two consecutive clusters of earthquakes. Physica A., 338: 201-205.

27. McGuire, R.K., 1995, Probabilistic seismic hazard analysis and design earthquakes: Closing the loop. Bull. Seismolog. Soc. Am., 85: 1275-1284. 